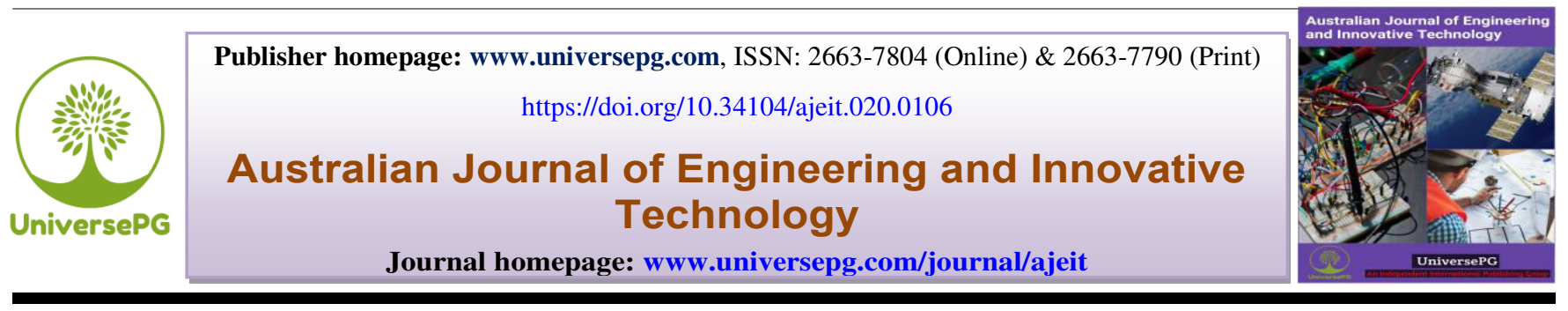

\title{
Influence of Potential Differential Voltage on Electric Resistance of Needle Punched Non-Woven Jute Fabrics
}

\author{
Sharmin Akter', Tahnin Bintay Kamal², Mahmuda Khatun ${ }^{3}$, Md. Mahbubul Alam³, Md. Zobaidul \\ Hossen $^{4}$, and Rezaul Karim ${ }^{5}$ \\ ${ }^{1}$ Textile Physics Division, Bangladesh Jute Research Institute, Dhaka, Bangladesh; ${ }^{2}$ Mechanical Processing Division, \\ Bangladesh Jute Research Institute, Dhaka, Bangladesh; ${ }^{3}$ Product Development Division, Bangladesh Jute Research Institute, \\ Dhaka, Bangladesh; ${ }^{4}$ Microbiology Department, Bangladesh Jute Research Institute, Dhaka, Bangladesh; and ${ }^{5}$ Dept. of \\ Textile Engineering, Sonargaon University, Dhaka, Bangladesh. \\ *Correspondence: rezatex99@gmail.com
}

\begin{abstract}
In this research, electrical resistance of needle punched non-woven jute fabric at different input voltage was measured. Here, to determine the electrical resistance, a device named the digital impedance meter has been used. The specific resistance for different gauge length of non-woven jute fabric has been observed to enhance the use of jute fabric for electrical purposes. It has been observed that the electrical resistance increased with higher value of gauge length and decreased with the increase of input voltage.
\end{abstract}

Keywords: Needle punched Non-woven, Voltage, Gauge length, Jute-fabric, and Specific resistance.

\section{INTRODUCTION}

There are many kinds of fibre in the world. Textile fibre is one of them. Textile fibres are the fibres which have a high length to width ratio with suitable characteristics for being processed into fabric and the smallest component that can be separated from the fabric (Belal, 2009). Textile fibres are two typesNatural fibre and Man-made fibre. But natural fibres are always preferable than the Man-made fibre for their extra ordinary properties. Jute is one of the most common natural fibres in the world (Karim et al., 2019). It is generally known as Golden fiber, because of its beautiful natural golden color. Like other natural fibre, Jute fibre also has many advantages which are low abrasion resistance, low density, high toughness, acceptable specific strength properties, good thermal properties, enhanced energy recovery, biodegrade- ability and so on (Mohanty et al., 2000; Cantero et al., 2003; and Bullions et al., 2004)

Jute is one of the longest, soft, shiny and mostly used vegetable fiber that can be spun into coarse, strong threads. It is produced from the plants in the genus Corchorus, family Tiliaceae. Jute is one of the cheapest natural fibres. It is second only to cotton in amount produced and variety of uses. The main materials of jute composition are the plant materials cellulose (a major component of plant fibre) and lignin (major components of wood fibre). For this reason it is a lingo cellulosic fibre which is partially a textile fibre and also partially wood. It falls into the bast fibre category (fibre collected from bast or skin of the plant) along with kenaf, industrial hemp, flax (linen), ramie, etc (Sengupta, 2010). 
Textile fabrics are divided into four categories. They are- Woven, Knitted, Non-woven and Braided. In this experiment we studied on Non-woven jute fabric. Non-woven fabrics are flexible, porous and contain one or more fibre layers. The separate fibre may be in one direction or in random directions. In this fabric, fibres are bonded together by chemical, mechanical or thermal bonding. But to produce non-woven fabric from jute fibres different techniques like, stitch bonding, needle punching, hot calendaring, oven bonding, hydro entanglement, hot air thermal bonding etc. are used (Maity et al., 2012). Needle punching is one kind of mechanical bonding system that is used to produce non-woven fabric. The needle punching process is well suited to produce medium and heavy weight non-woven from $300 \mathrm{gsm}$ to $3000 \mathrm{gsm}$ (Debnath, 1983). This system is very suitable for jute non-woven industry because of its higher productivity and low wage component of the production cost associated with it (Islam et al., 2019).

This technology also offers a means of diversifying into various value added product, which would fetch better returns to the industry using even waste fibres. Needle punched non-woven jute fabric is generally used for packaging, cushioning, carpet under laying, etc. (Sengupta and Sengupta, 2012). Sengupta et al. (1999) have also studied the air permeability property of jute non-woven fabrics. In another study, Sengupta et al. (2008) have studied the use of needle-punched non-woven jute fabric as reinforcement in composite. Electrical properties like conductivity, resistance, insulation, etc. are important in many textile applications such as apparel, gloves, and jackets for electrical work, building insulation, automobiles, aircraft and industrial process equipment and floor covering where high voltage machines are kept. For long time, a different textile material has been used as insulator. From the ancient age, the conductive wire is wrapped with cotton or silk yarns for insulation. Synthetic materials are widely used as insulator rather than natural textile material for low cost. The use of jute fabric as insulator will minimize the heat that is generated during the current flow through electrical wire in high voltage (Uddin et al., 2020).
The amount of heat which is generated during current flow through any fabrics in high voltage is a vital matter. The electrical resistance of a fabric or an object is a measure of the difficulty to pass an electric current through that conductor. Accordance with Ohm's law (I=V/R), resistance determines the amount of current passing through the object for a given potential difference across the object. Where $\mathrm{I}=$ the current in ampere, $\mathrm{V}=$ the potential difference across the object in volts and $\mathrm{R}=$ the resistance in ohm. Different textile materials like cotton, silk yarns are usually used as insulator. But the utilization of textile materials has been reduced with extensive use of the synthetic polymers (Sengupta et al., 1985). It has been reduced the cost of insulation. On the other hand, the natural fibre jute has gained more attention because of its availability, less costly and also for eco-friendly uses. There is enough scope of using jute fabrics as insulator.

\section{MATERIALS AND METHODS}

Materials - Non-woven jute fabric has been collected from Janata Jute Mills Ltd., Bangladesh. It was needle punched non-woven jute fabric. Raw jute fibre was softened by using JBO oil. The GSM value of non-woven jute fabric is $400 \mathrm{~g} / \mathrm{m}^{2}$. Fig 1 shows the non-woven jute fabric. Two basic steps are involved in the manufacturing process of needle punching jute non-woven fabric:

a. The jute sliver web produced from finisher card machine is fed into a machine with specially designed needles.

b. The sliver webs move on a substrate between a metal bed plate and a stripper plate; the needles punch through the plates and the sliver web, reorienting the fibres so that bonding occurs among the individual fibres.

Methods - The experiment is performed by using Digital Impedance Meter. The Fig 2 shows the digital impedance meter. This meter is a digital format of LRC circuit. Samples are placed at fixed terminal of the meter and the expected results are shown on the screen. The specific resistance is measured for different voltages and also for different gauge length. 
At first non-woven jute fabric sample of 1.0 gauge length is placed on respective terminal.

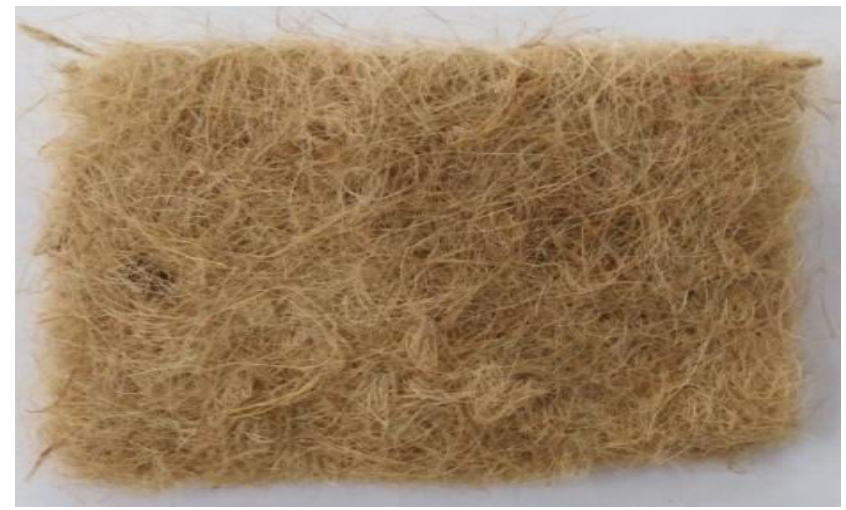

Fig 1: Needle punched non-woven jute Fabric.

The sample is in series with a known resistance $10 \mathrm{M} \Omega$ and is connected to a DC power supply. The voltage is changed from 60 to 100 volts and corresponding current through the sample is measured. The current is taken after 10 seconds to measure resistance. These steps are repeated for non-woven jute fabric of $1.5 \mathrm{~cm}$ gauge length and also for $2.0 \mathrm{~cm}$ gauge length. Experimental readings are taken to draw a V-I characteristics curve. The V-I characteristics of each slope are determined. This experiment is performed at room temperature $30^{\circ} \mathrm{C}$.

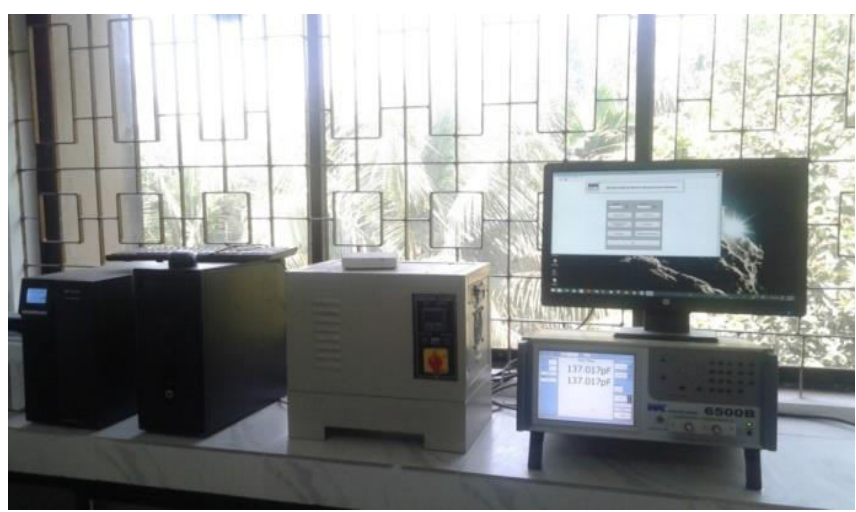

Fig 2: The digital impedance meter.

\section{RESULT AND DISCUSSION}

Effect of Voltage: Electrical resistance test were carried out for non-woven jute fabrics at three different gauge lengths, viz $1.0,1.5$ and $2.0 \mathrm{~cm}$. The tests were performed in three voltage levels, viz 60, 80 and 100 volts. Fig 3 shows that for different input voltage, specific resistance increases with the increase of gauge length.
Different Resistance at Voltage 60 in Nonwoven jute fabrics at different gauge length

300

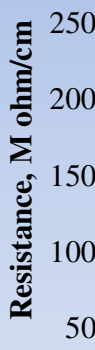

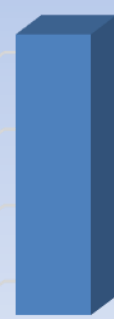

1

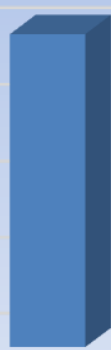

1.5

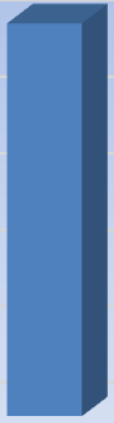

2
Gauge Length, cm

Fig 3(a): Different resistance at voltage 60 in nonwoven jute fabrics at different gauge length.

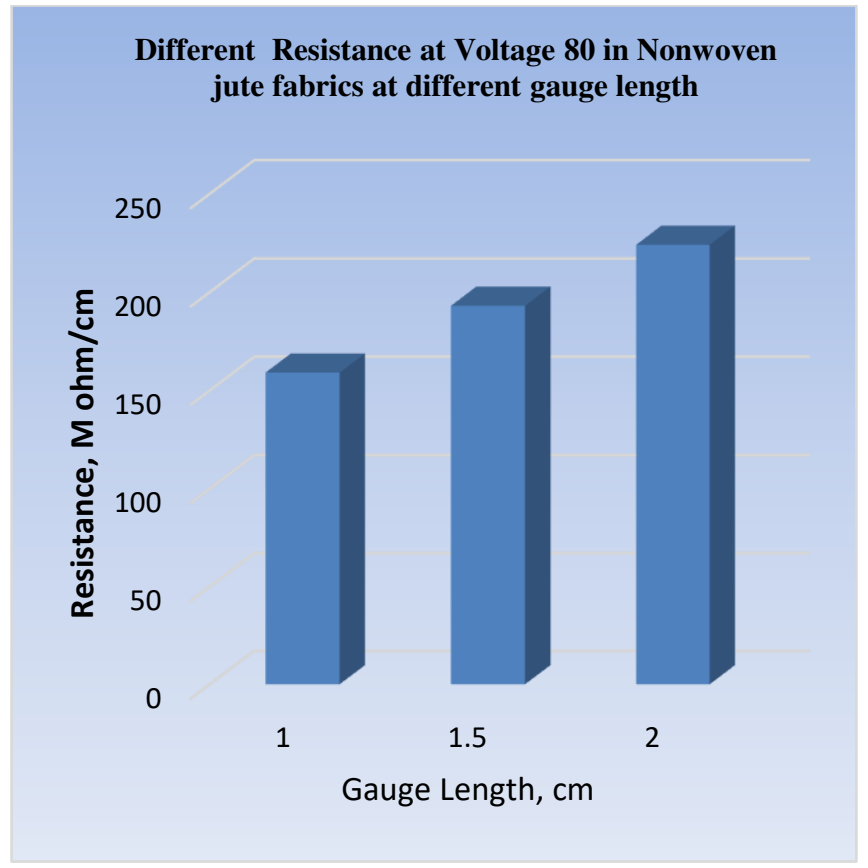

Fig 3(b): Different resistance at voltage 80 in nonwoven jute fabrics at different gauge length.

Fig 3(a) shows that at 60 volts of input voltage, the value of specific resistance is high for $2 \mathrm{~cm}$ of gauge length and it increases with the higher value of gauge length of fabric. The rate of increase of specific resistance for 1 to $1.5 \mathrm{~cm}$ of gauge length is $11.45 \%$ 
where the rate of increase for 1.5 to $2 \mathrm{~cm}$ of gauge length is $25.35 \%$.

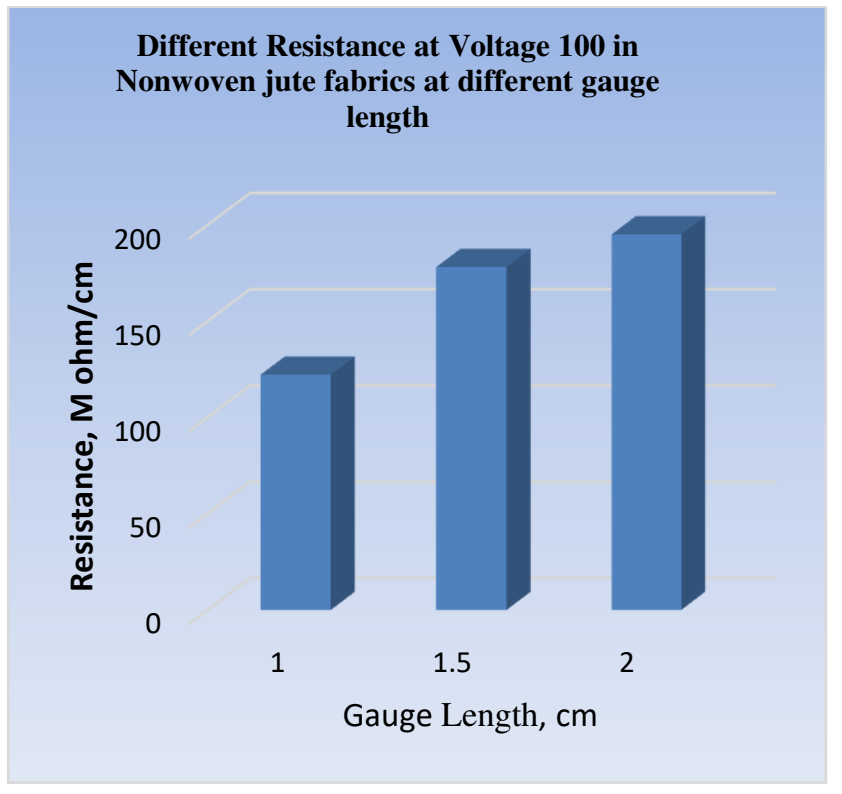

Fig 3(c): Different resistance at voltage 100 in nonwoven jute fabrics at different gauge length.

From Fig 3(b), it is shown that at 80 volts, the rate of change is $21.35 \%$ for 1 to $1.5 \mathrm{~cm}$ and $16.06 \%$ for 1.5 to $2 \mathrm{~cm}$ of gauge length. And from Fig 3(c), we have seen that the specific resistance is increased $9.55 \%$ for the change of gauge length from 1.5 to $2 \mathrm{~cm}$.

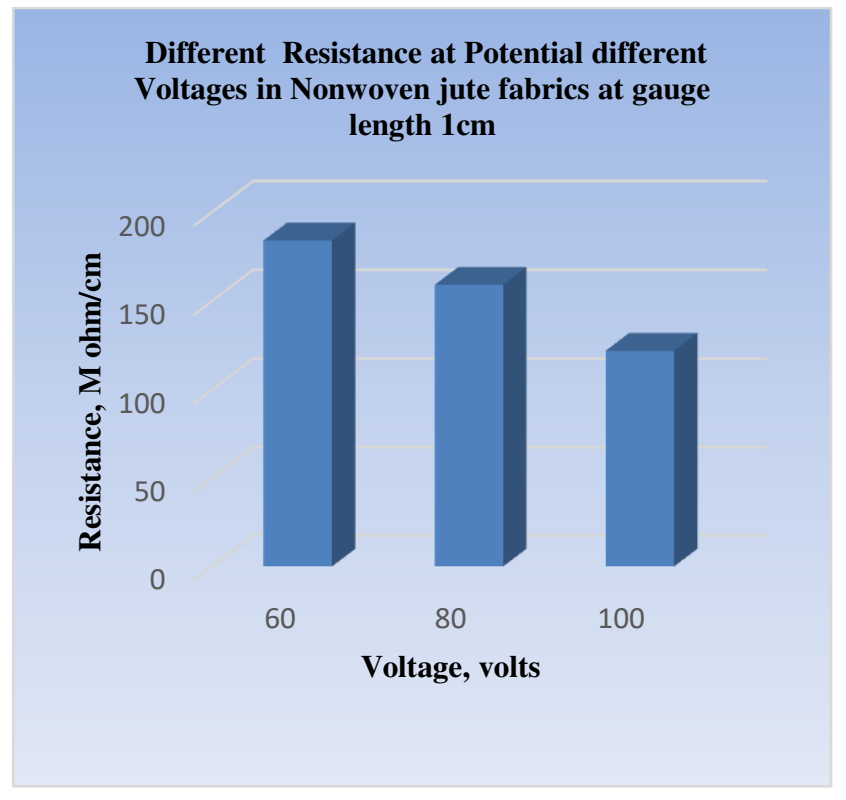

Fig 4(a): Different resistance at potential different voltages in non-woven jute fabrics at gauge length $1 \mathrm{~cm}$.

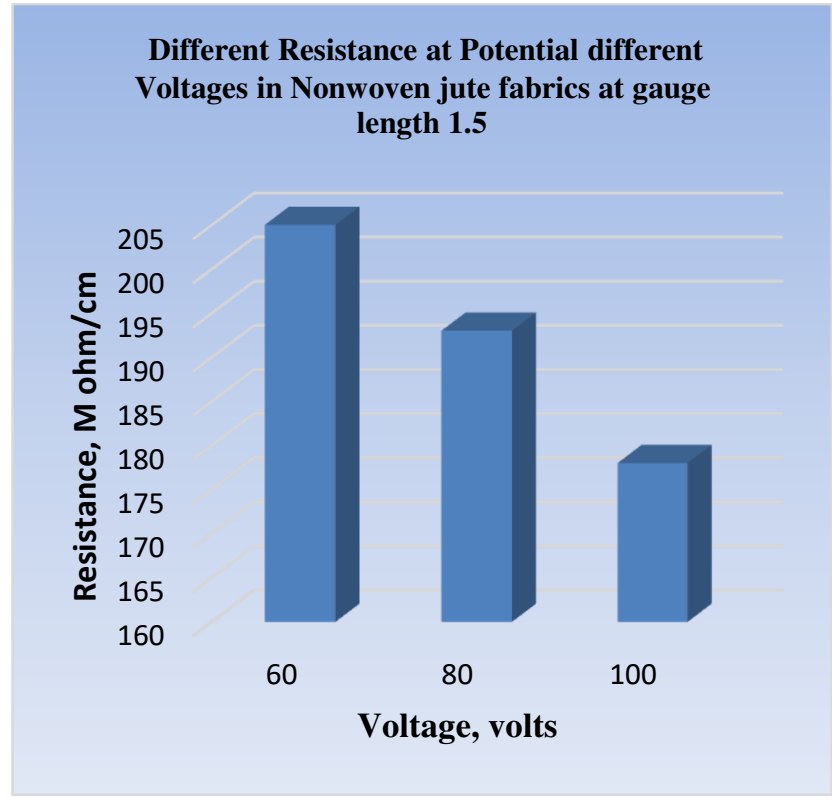

Fig 4(b): Different resistance at potential different voltages in non-woven jute fabrics at gauge length 1.5.

Effect of Gauge Length: Fig 4 shows resistance against different gauge lengths in different input voltages. It shows that resistance increases with the increase in gauge length. Fig 4(a), Fig 4(b), and Fig 4 (c) shows the result for $1,1.5$, and $2 \mathrm{~cm}$ of gauge length respectively.

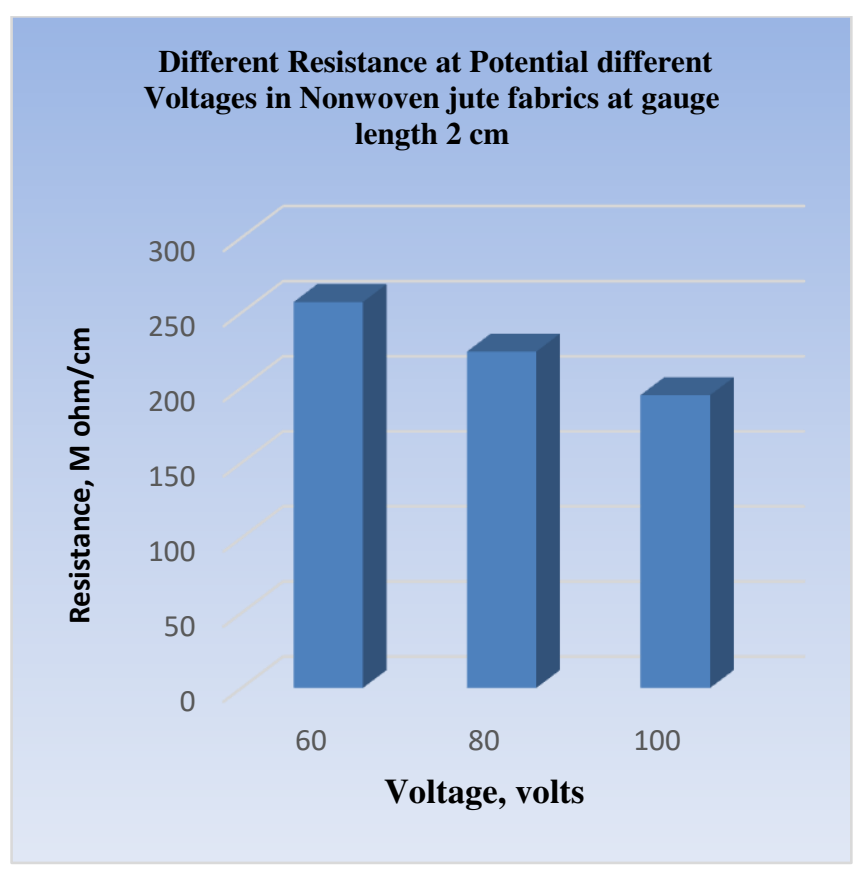

Fig 4(c): Different resistance at potential different voltages in non-woven jute fabrics at gauge length 2 $\mathrm{cm}$. 
Fig 4(a) shows a decreasing trend of specific resistance for the non-woven jute fabric of $1 \mathrm{~cm}$ gauge length. The value of resistance is higher for 60 volts and it decreases with the increase of input voltage. The percentage of decrease is $13.5 \%$ for $60-80$ volts and $23.27 \%$ for $80-100$ volts. Fig 4(b) and Fig 4(c) also show the same trend of decreasing. But the rate of change is $10.85 \%$ and $12.84 \%$ for $60-80$ volts for 1.5 and $2 \mathrm{~cm}$ of gauge length respectively. The rate of decrease is higher for $80-100$ volts at $2 \mathrm{~cm}$ of gauge length compare to 1 and $1.5 \mathrm{~cm}$ of gauge length and the value is $12.95 \%$.

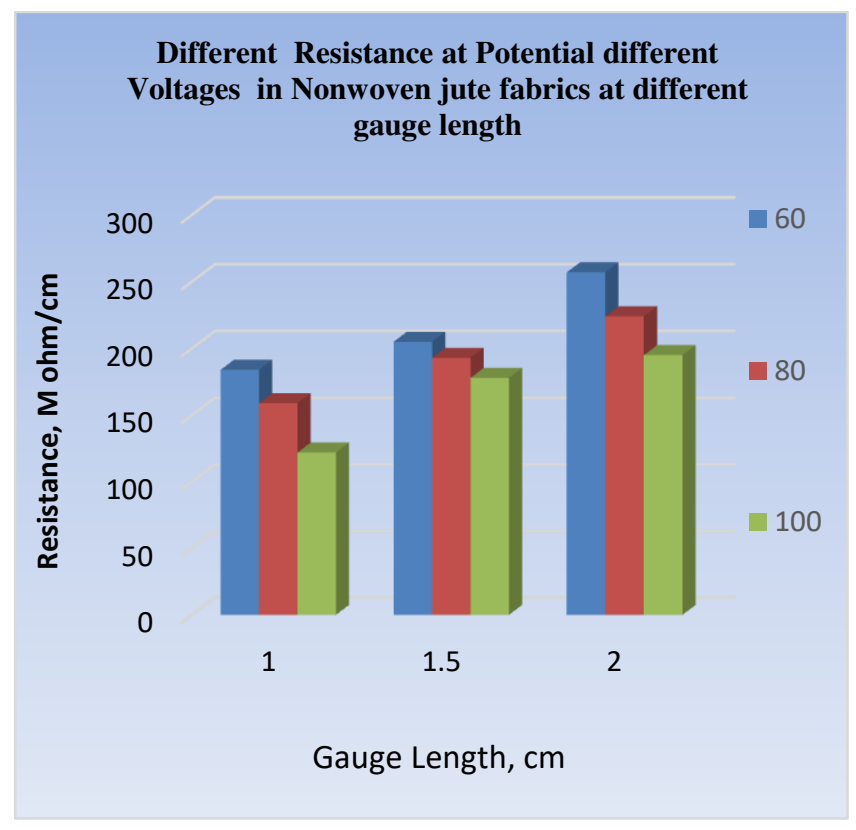

Fig 5: Electrical resistance at different voltages at different gauge length.

From Fig 5, it is observed that the specific resistance is increased with the decrease of input voltage and increased with the increase of gauge length. From this, we can say that insulating property of fabric increases with the increase in length between two measuring jaws. The rate of change is not same for different gauge length. The change rate is higher for $2 \mathrm{~cm}$ gauge length. At $1.5 \mathrm{~cm}$, difference between the values of specific resistance at different voltages is less than other gauge length of fabric.

\section{CONCLUSION}

Electrical resistance of nonwoven jute fabrics decreases with the increase of input voltage. For non- conducting material resistance remain constant with the increase of voltage as current also increases with the increase of voltage. But from this study, we see that current is not increasing proportionately and hence resistance decreases. The significant fall at high voltages is usual breakdown of insulation. It signifies that if we want to use jute fabrics as electrical purposes, we should be careful for using higher voltages. The resistance increases with the increase of gauge length of fabrics. It means that, the gauge length is more important matter of consideration for using non-woven jute fabrics as insulator.

\section{ACKNOWLEDGEMENT}

We are greatly acknowledged to BJRI, Dhaka, Bangladesh, where this research work has been performed. The authors would like to convey their heartiest thanks to all officers and lab assistants in BJRI for their continuous support and help to make this work a successful.

\section{CONFLICTS OF INTEREST}

The authors declare they have no competing conflict of interests with respect to the publication of the present research.

\section{REFERENCES}

1) Belal, S.A. (2009). Understanding Textiles for A Merchandiser, BMN3 Foundation, Dhaka, Bangladesh, 585-586.

2) Bullions TA, Gillespie RA, Price-O'Brien J. and Loos AC. (2004). The effect of maleic anhydride modified polypropylene on the mechanical properties of feather fiber, kraft pulp, poly propylene composites. J. App Polym. Sci., 92, 3771-3783. https://doi.org/10.1002/app.20369

3) Cantero G, Arbelaiz A, Llano-Ponte R and Mondragon I. (2003). Effects of fiber treatment on wettability and mechanical behavior of flax/polypropylene composites. Compos Sci. Technol., 63, 1247-1254.

4) Debnath R C (1983). The Indian Textile Journal, 93, 149. 
5) Islam KA, Deeba F, and Hassan MKA. (2019). Dust Ion Acoustic Solitary Waves in Multi-Ion Dusty Plasma System with Adiabatic Thermal Change, Aust. J. Eng. Innov. Technol., 1(5), 1-5. https://doi.org/10.34104/ajeit.019.0105

6) Karim R, Razzak A, Mahabubuzzaman AKM, and Shahid A. (2019). Comparison of the Quality Parameter between Cotton and Melange process, Aust. J. Eng. Innov. Technol., 1(6), 21-30. https://doi.org/10.34104/ajeit.019.21030

7) Maity S., Singha K., Gon D.B., Paul P., Singha M. (2012). A Review on Jute Nonwovens: Manufacturing, Properties and Applications. International Journal of Textile Science, 1(5), 36-43.

8) Mohanty AK, Misra M and Hinrichsen G. (2000). Biofibers, biodegradable polymer and biocomposites: An overview. Macromol. Mater. Eng., 276, 1-24.

9) Sengupta S. (2010). Sound Reduction by Needle-Punched Nonwoven Fabrics, Indian J Fibre Text Res., 35(3), 237-242.

10) Sengupta, A.K., Sinha A.K. and Debnath C.R. (1985). Needle Punched Jute Floor Coverings,
Part I: Influence of Fibre\& Process Variables on Tensile Properties of Fabrics, Indian J Text Res., 10(3), 91-96.

11) Sengupta S., and Sengupta, A. (2012). Electrical resistance of jute fabrics. Indian Journal of Fibre\& Textile Research, 37(1), $55-59$.

http://hdl.handle.net/123456789/13686

12) Sengupta S, Samajpati S, and Ganguly P K. (1999). Air permeability of jute based needlepunched nonwoven fabrics. Indian Journal of Fibre \& Textile Research, 24, 103-110.

13) Sengupta Surajit, Sambhu Nath Chattopadhyay, Soma Samajpati, and Abhindra Day (2008). Use of Jute needle-punched nonwoven fabric as reinforcement in composite. Indian Journal of Fibre \& Textile Research, 33, 3744.

14) Uddin MM, Karim R, Kaysar MA, Dayan MAR, and Islam KA. (2020). Low-cost jutecotton and glass fibre reinforced textile composite sheet, Int. J. Mat. Math. Sci., 2(1), $1-7$.

https://doi.org/10.34104/ijmms.020.01007 